\title{
Is Meaningful Work a Stronger Predictor of Innovation Than Transformational Leadership?
}

\author{
Andrew Kenneth MacLachlan Sedger \\ Charles Sturt University \\ Locked Bag 588, Wagga Wagga, NSW 2678, Australia, \\ E-mail: andrewsedger@gmail.com
}

\author{
Karl Kilian Konrad Wiener (Corresponding author) \\ Charles Sturt University \\ Locked Bag 588, Wagga Wagga, NSW 2678, Australia \\ E-mail: karl1.research@gmail.com
}

Received: December 17, 2020

doi:10.5296/wjbm.v7i2. 18090
Accepted: August 6, $2021 \quad$ Published: August 20, 2021

URL: https://doi.org/10.5296/wjbm.v7i2.18090

\begin{abstract}
\section{Purpose:}

Innovation is recognised as a key driver of business and economic growth. However, many organisations struggle to implement or encourage innovation successfully. A number of factors, including the demonstration of transformational leadership, have been examined in encouraging innovation behaviour among employees. 'Meaningful work' is seen as an additional factor influencing innovation but has received little attention in this field.
\end{abstract}

\section{Design:}

Drawing on both an emerging body of research on meaningful work and a leading model of creativity and innovation in organisations, this exploratory study of 100 Australian adult employees investigated the additional predictive value of both meaningful work and transformational leadership on innovation behavior.

\section{Findings:}

Results showed that meaningful work was positively correlated with, and predicted, innovation, while transformational leadership did not contribute to innovative behaviour. 


\section{Macrothink}

World Journal of Business and Management

ISSN 2377-4622

2021, Vol. 7, No. 2

\section{Implications:}

This finding has implications for organisations fostering innovation by helping them better understand the impact meaningful work could have on their innovation objectives.

\section{Originality:}

This is one of the first studies examining the relationship between innovation, meaningful work, and transformational leadership in a population of employed adults.

Keywords: Meaningful work, Innovation behaviour, Transformational leadership 


\section{Introduction}

Innovation is seen as fundamental to the sustainable growth and success of organisations (Gronum et al., 2015; West, 2002) and for national economic growth (Pricewaterhouse Coopers, 2014). But innovation is often difficult to achieve, and many organisations report poor innovation outcomes (Kuratko et al., 2014). Understanding the complex factors that help or hinder innovation can help organisations improve the way they implement, support and grow innovation.

One of the key drivers of innovation behaviour among employees is leadership (Crossan \& Apaydin, 2010), and specifically, the extent to which leaders display a transformational leadership style (Mumford, 2014). However, an emerging body of research suggests that the concept of meaningful work could also be an important factor in employee innovation behaviour. Over the past decade, several management theories have recognised the importance of meaningful work to a range of employee and organisational outcomes (Lips-Wiersma \& Wright, 2012) including organisational commitment, work engagement, psychological well-being, job satisfaction, motivation and stress reduction. Amabile and Pratt (2016) have theorised that meaningful work plays an important role in influencing innovation behaviour, and they introduced meaningful work as one of four major new constructs in the widely-cited dynamic componential model of creativity and innovation in organisations (Amabile 1988).

This pilot study explores the impact that meaningful work and transformational leadership have on innovation behaviour in a sample of adult Australian employees.

\section{Role of Transformational Leadership in Innovation}

A systematic review of 27 years of research findings conducted by Crossan and Apaydin (2010) suggested that the role of leadership at all levels of an organisation is paramount for spearheading innovation as a process, and maintaining its momentum until innovation as an outcome ensues. One aspect of leadership that has been strongly linked to increased innovation behaviour among employees is the extent to which leaders display a transformational leadership style (Afsar et al., 2014; Friedrich et al., 2010; Reuvers et al., 2008). According to Bernard (1999), transformational leaders uplift the morale, motivation and morale of their followers, whereas transactional leaders cater to their followers' immediate self-interests.

Scholars have explored the mechanisms through which transformational leadership influences innovation behaviour. For example, Khalili (2016) argued that the support and consideration shown by transformational leaders assist employees in overcoming their fears of challenging the routine ways of doing things and encourages them to seek new and fresh approaches to their work. Transformational leaders are also likely to enhance innovation through the application of individualised consideration, charisma and inspirational motivation (Oke et al., 2009). Shunlong and Weiming (2012) suggested that it was the vision and charisma dimension of transformational leadership that was responsible for fostering positive effects on employee innovation behaviour. Consistent with previous research, this study 
expects to find a positive relationship between transformational leadership and innovation behaviour.

\section{Growing Recognition of Meaningful Work}

One aspect of innovation that has received little attention, however, is the construct of 'meaningful work'. This is unusual because, over the last two decades, there has been a growing interest in meaningful work in the organisational behaviour literature (Lips-Wiersma et al., 2016). The increased focus on meaningful work has been linked to the rising interest in social and environmental awareness and business ethics (Michaelson, 2010) together with a renewed interest in employee well-being, individual strengths and human flourishing that has grown out of the positive psychology movement (Lips-Wiersma \& Wright, 2012). In fact, the construct of meaningful work is considered to be a cornerstone of human flourishing (Seligman et al., 2005).

As interest in meaningful work grows, so too do attempts to define and operationalise this construct. Building on qualitative research, Lips-Wiersma and Wright (2012) suggested meaningful work includes four key dimensions: 'unity with others', 'developing the inner self', and 'serving others and expressing full potential'. (Steger et al., 2012) defined meaningful work as a "subjectively meaningful experience consisting of experiencing positive meaning in work, sensing that work is a key avenue for making meaning, and perceiving one's work to benefit some greater good" (p. 322). Bailey and Madden (2016) defined meaningful work as arising "when an individual perceives an authentic connection between work and a broader transcendent life purpose beyond the self" (p. 55). The one factor all three definitions have in common is that meaningful work involves an 'other' orientation, i.e. serving a greater or transcendent good, or serving others.

Meaningful work has been shown to be positively related to a range of organisational and employee variables, such as work engagement and organisational commitment (Geldenhuys et al., 2014; Jung \& Yoon, 2016), job satisfaction (Sparks \& Schenk, 2001) and overall well-being (Allan et al., 2015), and negatively related to disengagement and exhaustion (Fairlie, 2011). Arnoux-Nicolas et al. (2016) found that meaningful work partially mediated the relationship between perceived negative working conditions and turnover intention. Meaningful work has also been shown to play a role in the impact of transformational leadership. For example, meaningful work partially mediated the relationship between transformational leadership and affective organisational commitment (Pradhan \& Pradhan, 2016), task performance (Aryee et al., 2012), and positive affective well-being (Arnold et al., 2007). Meaningful work fully mediated the relationship between transformational leadership and promotive voice behaviour in organisations (Chen et al., 2018).

\section{Meaningful Work and Innovation}

Only a few studies have examined the relationship between meaningful work and innovation, although this has typically been in the context of other variables. Pradhan and Jena (2019) found that meaningful work partially mediated the relationship between transformational leadership and innovative work behaviour. Singh et al. (2020) found that meaningful work 
mediated the impact of human resource practices and innovative work behaviour, while Cai et al. (2018) found that meaningful work conditionally mediated the relationship between servant leadership and innovative work behaviour. A study of public-school teachers in Nigeria found that meaningful work mediated the relationship between intrinsic motivation and teachers' innovative work behaviour (Bawuro et al., 2019).

Other research has examined the connection between meaningful work and creativity rather than innovation, per se. In a review of different ways of conceptualising meaningful work, Lepisto and Pratt (2017) argued that meaningfulness can be a source of persistence in creative work and can encourage employees to remain with a creative task in the face of setbacks and challenges. In reviewing empirical studies involving creativity, it is important to recognise that creativity and innovation are distinct but related concepts. In an organisational context, creativity is defined as the production of novel or useful ideas by an individual or group, whereas innovation is defined as the successful implementation of creative ideas (Amabile \& Pratt, 2016). In this sense, creativity can be considered as a 'precursor' of innovation, but not innovation itself.

Based on the findings of studies that have shown relationships between the constructs of meaningful work, innovation and creativity, this study predicts a positive relationship between meaningful work and innovation behaviour.

\section{Is Meaningful Work More Important for Innovation than Transformational Leadership?}

The relationship between meaningful work and transformational leadership has not been extensively examined; however, one study suggests that the link may be tenuous. Bailey and Madden (2016) conducted qualitative research with 135 workers in the UK, and found that the role of leadership in helping employees find meaning is "complex and profound, going far beyond the relative superficialities of satisfaction or engagement - and almost never related to one's employer or manager." (p. 56).

Amabile and Pratt (2016) theorised that this is a relationship between meaningful work, leadership and innovation behaviour. Their model, known as the dynamic componential model of creativity and innovation in organisations is a revised and updated version of an earlier componential model of creativity and innovation, first proposed over a decade ago (Amabile, 1988). In the recent revision, Amabile and Pratt (2016) introduced the concept of meaningful work as one of four major new constructs. Their rationale for including meaningful work was based on a study of people working on important innovation projects within their organisations (Amabile et al., 2004). The authors of that study examined over 12,000 diary entries and found that on days when people reported high levels of positive subjective experience, the most prominent work event was making progress in 'meaningful work'. Based on these findings and their own theories of organisational creativity and innovation, Amabile and Pratt suggested that meaningful work can influence creativity and innovation. They also argued that meaningful work is more influential than leadership behaviour: "Put simply, if people do not see innovative or creative work as meaningful, it seems unlikely that leaders' statements and actions about the importance of innovation will 
be motivating. By contrast, such statements are likely to be highly motivating for those who do find innovative and creative work meaningful" (Amabile \& Pratt, 2016).

\section{Research Hypothesis and Expectations}

The dynamic componential model of creativity and innovation in organisations suggests that meaningful work is a critical component of innovation and may potentially be more influential than transformational leadership. The current study explores this question empirically by surveying a sample of adult Australian employees and predicts that the relationship between meaningful work and innovation will be stronger than transformational leadership and innovation after controlling for age, gender and educational level.

\subsection{Demographic variables}

The relationship between innovation and demographics is complex. For example, Nählinder et al. (2015) suggest that gender bias is built into the methodology of many innovation studies, leading to women appearing less innovative. But when these researchers applied a gender-aware operationalisation of innovation, they found no significant difference in innovativeness between men and women. Regarding the impact of age, Frosch (2011) argues that studies showing innovation peaking between 35 and 50 years of age often contain methodological constraints such as selectivity biases and unobserved heterogeneity. Citing longitudinal studies, she contends it is very likely that older workers fare much better in innovation than previous cross-sectional evidence suggests. Likewise, there are conflicting findings in relation to the impact of educational attainment on innovation, with some studies showing a positive relationship at the country level (Makkonen \& Inkinen, 2013) and others showing no relationship at the individual level (Hammond et al., 2011). Because of the complexity and ambiguity surrounding the impact of age, gender and educational level on innovation, this study sought to control for these variables.

\section{Method}

\subsection{Participants}

Participants in this study were employed Australians aged 18 years and over. Most were recruited via LinkedIn and Facebook as a result of several posts inviting people to complete an online survey about leadership, innovation and meaningful work. The posts were made to the author's social media accounts, as well as to relevant social media groups (e.g. Organisational Psychology in Australia's Facebook page). Participants were also recruited via Mechanical Turk (MTurk). A total of 108 completed responses to the online survey were collected.

\subsection{Measures}

\subsubsection{Transformational Leadership}

Participants completed the Global Transformational Leadership scale, a short measure of transformational leadership developed by Carless et al. (2000). The seven item survey has been used in international leadership studies to assess a single global construct of 
transformational leadership (Bass \& Riggio, 2006). Answers were given on a five point Likert-scale from "Rarely or never" to "Very frequently, if not always" to questions including "My manager communicates a clear and positive vision of the future" and "My manager treats staff as individuals, supports and encourages their development". The range of possible scores is 7-35. The Global Transformational Leadership scale was chosen over the more commonly used Multifactor Leadership Questionnaire (Avolio et al., 1999) because the former uses fewer items (seven versus 20) yet has identical reliability to the latter. The total score on the Global Transformational Leadership scale has also been found to correlate strongly with the Multifactor Leadership Questionnaire. However, the Global Transformational Leadership scale measures a broader range of transformational leadership behaviours (Carless et al., 2000), including 'innovative thinking'. The Global Transformational Leadership scale has been shown to have high reliability ( $\alpha=.93$ ) (Carless et al. 2000). In this study, the reliability of the scale was high $(\alpha=.91)$.

\subsubsection{Meaningful Work}

Meaningful work was operationalised by the Work and Meaning Inventory (Steger et al., 2012). The Work and Meaning Inventory is a ten item test with the total score reflecting the extent to which people see their work as being personally significant, as providing an opportunity for meaning making and as a way to make a contribution beyond themselves. Answers were given on a five point Likert-type scale ranging from "Absolutely untrue" to "Absolutely true" to questions including "I have a good sense of what makes my job meaningful" and "I have discovered work that has a satisfying purpose". The range of possible scores is $10-50$. The total Work and Meaning Inventory scale internal consistency has been shown to be high $(\alpha=.93)$ and validity and factors structure estimates are solid (Steger, Dik, \& Shim, In press). In this study, the reliability of the total scale was high ( $\alpha$ $=.93)$.

\subsubsection{Innovation Behaviour}

Innovation behaviour was assessed using the Innovation Behaviour Inventory, a relatively new scale developed by Lukes and Stephan (2017). The 23 item Innovation Behaviour Inventory covers seven aspects of employee innovation behaviour, which address a wide spectrum of activities believed to constitute the full cycle of innovation in an organisation. Answers were given on a five point Likert-type scale ranging from "Fully disagree" to "Fully agree". The range of possible scores is 23-115. Items measure idea generation (e.g. "I try new things at work"), idea search (e.g. "I try to get new ideas from colleagues or partners), idea communication (e.g. "When I have a new idea, I try to persuade my colleagues of it"), implementation starting activities (e.g. "I develop suitable plans and schedules for the implementation of new ideas"), involving others (e.g. "I try to involve key decision makers in the implementation of an idea), overcoming obstacles (e.g. "I usually do not finish until I accomplish my goal"), and innovation outputs (e.g. "Many things I came up with are used in our organisation"). The Innovation Behaviour Inventory has been shown to have acceptable reliability ( $\alpha$ coefficients for the seven subscales ranged from .60 to .93) and has shown to have factorial, criterion, convergent and discriminant validity, and cross-cultural equivalence 


\section{Al Macrothink}

World Journal of Business and Management

ISSN 2377-4622

2021, Vol. 7, No. 2

(Lukes \& Stephan, 2017). In this study, the reliability of the total score for the Innovation Behaviour Inventory was high $(\alpha=.92)$.

\section{Results}

The data set was checked for outliers, requiring the deletion of seven univariate outliers and one multivariate outlier. Normality assessment showed that skewness for the Global Transformational Leadership scale and the Innovation Behaviour Inventory were within acceptable parametric perimeters, whilst Work and Meaning Inventory scores were skewed. Tabachnick and Fidell (2014) argued that for larger samples, a variable with statistically significant skewness often does not make a substantive difference in subsequent statistical analyses. Consistent with Tabachnick and Fidell (2014), no further adjustments were made to the data to comply with normality parametrics.

\subsection{Descriptive Statistics}

Descriptive and inferential analyses were conducted using SPSSv25. A demographic profile of the remaining 100 participants is provided in Table 1. The majority of respondents $(71 \%)$ were in full-time employment, while almost half (49\%) had postgraduate qualifications. There was a higher proportion of female (60\%) compared to male (40\%) respondents. Ages ranged from 19 to 65 , with an average of 42.98 years $(S D=9.53)$.

Table 1. Demographic profile of respondents $(n=100)$

\begin{tabular}{llll}
\hline Category & & Frequency & $\%$ \\
\hline Gender & & 60 & 60 \\
& Female & 40 & 40 \\
$\quad$ Male & & \\
Education level completed & 1 & 1.0 \\
$\quad$ Some high school & 1 & 1.0 \\
Year 10 high school & 5 & 5 \\
Year 12 high school & 9 & 9 \\
TAFE or vocational qualification & 35 & 35 \\
Bachelors degree & 49 & 49 \\
Postgraduate degree & & \\
Furrent employment status & 71 & 71 \\
Full-time & 22 & 22 \\
Part-time & 7 & 7 \\
\hline
\end{tabular}

The mean score for the Work and Meaning Inventory was $40.30(S D=7.97)$, the mean score for the Global Transformational Leadership scale was $26.16(S D=5.10)$, and the mean score for the Innovation Behaviour Inventory was $92.82(S D=11.12)$. 


\section{Macrothink}

World Journal of Business and Management

ISSN 2377-4622

2021, Vol. 7, No. 2

Bivariate correlations were conducted (see Table 2). Consistent with expectations, a positive correlation was found between meaningful work and innovation behaviour $(r=0.38, p<0.01)$. A negative correlation was found between gender and meaningful work, where women scored significantly higher than men. There was no significant correlation between transformational leadership and innovation, which is inconsistent with findings in the literature and inconsistent with the expectations of this study.

Table 2. Correlations of variables $(n=100)$

\begin{tabular}{|c|c|c|c|c|c|c|}
\hline Variable & 1 & 2 & 3 & 4 & 5 & 6 \\
\hline 1. Age & - & & & & & \\
\hline 2. Gender & .00 & - & & & & \\
\hline 3. Education & .05 & .04 & - & & & \\
\hline 4. Transformational leadership & -.11 & -.11 & -.12 & - & & \\
\hline 5. Innovation behaviour & .14 & .00 & -.01 & .09 & - & \\
\hline 6. Meaningful work & .06 & $-.21 *$ & .12 & .09 & $.38 * *$ & - \\
\hline
\end{tabular}

A three-stage hierarchical regression was conducted with innovation behaviour as the dependent variable to test the additional predictive value of meaningful work on innovation. Age, gender and education level were entered at stage one to control for demographic variables. Transformational leadership was added at stage two and meaningful work at stage three. Regression statistics are shown in Table 3.

Table 3. Hierarchical regression analysis for variables predicting innovation behaviour $(n=100)$

\begin{tabular}{llll}
\hline Variable & B $(\mathbf{S E})$ & beta & $\mathbf{t}$ \\
\hline Model 1 & & & \\
$\quad$ Constant & $86.57(8.26)$ & & 1.37 \\
Age & & .14 & .01 \\
Gender & & .001 & -.12 \\
Education & -.01 & \\
$F(3,96)=.63$ & & \\
$\mathrm{R}=.14$ & & & \\
$\mathrm{R}^{2}=.02$ & & & \\
\hline Model 2 & & .15 & 1.47 \\
Constant & $78.79(11.1)$ & .01 & .13 \\
Age & & -.001 & -.009 \\
Gender & & .11 & 1.05 \\
Education & & & \\
Transformational leadership & & & \\
\hline
\end{tabular}




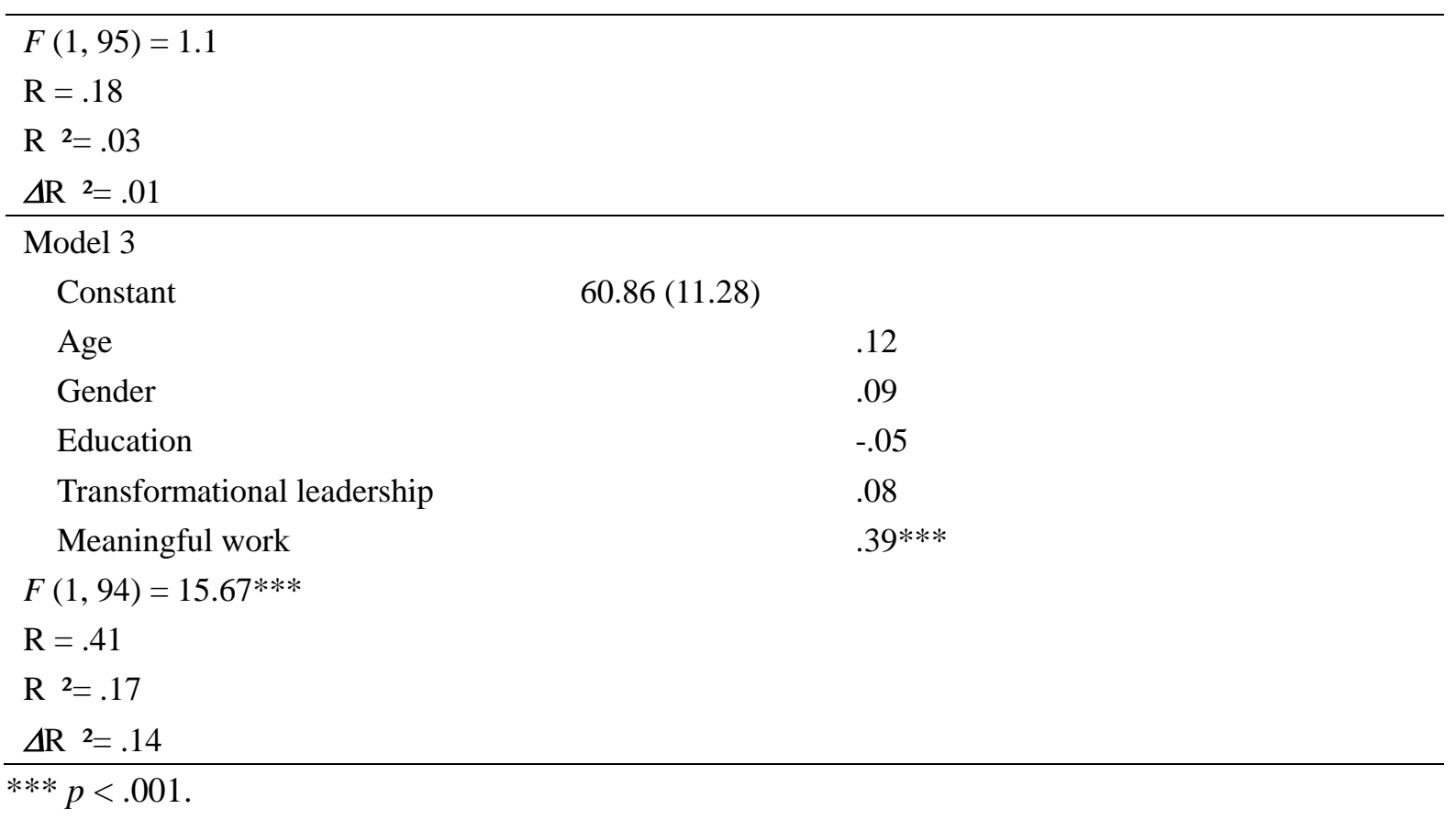

The third model of the hierarchical multiple regression revealed that age, gender, and education level did not predict innovation behaviour, and neither did transformational leadership. Introducing meaningful work contributed significantly to the regression model, $\mathrm{F}$ $(1,94)=15.67, \mathrm{p}<.001$, and accounted for $14 \%$ of the variation in innovation behaviour. This finding demonstrates that meaningful work is the only predictor of innovation, and transformational leadership was not a predictor on innovation in this study. The finding that transformational leadership did not predict innovation behaviour at all was unexpected and not consistent with the stated hypothesis.

\section{Discussion}

\subsection{Transformational Leadership and Innovation}

Contrary to expectations, this study did not find a positive relationship between transformational leadership and innovation. This result is inconsistent with the existing literature, which includes multiple studies that have established empirical support for this relationship (Afsar et al., 2014; Khalili, 2016; Nusair et al., 2012; Reuvers et al., 2008). There are a number of possible reasons for the inconsistency between the results of this study and previous studies, the first being the use of different scales to measure innovation behaviour. In this study, it was measured using the relatively new 23 item Innovation Behaviour Inventory developed by Lukes and Stephan (2017). In contrast, Nusair et al. (2012) used their own measure of innovation based on a six item scale developed by Scott and Bruce (1994). While the Scott and Bruce scale covers both idea generation and idea implementation, unlike the Innovation Behaviour Inventory it is a one-dimensional scale that does not differentiate between the various aspects of innovation behaviour. Two other studies, Khalili (2016) and Afsar et al. (2014), used a multi-dimensional scale developed by De Jong and Den Hartog (2010). Although that scale has some overlap with the Innovation Behaviour Inventory, it also 
has several shortcomings, including the fact that "the distinct aspects of innovation are captured in a summary fashion by three rather general items only" (Lukes \& Stephan, 2017). Furthermore, in the Khalili (2016) study the measure was not administered directly to employees, as it was in this study, but rather administered to managers who provided their views about the innovation behaviour of their employees.

Another reason for the discrepant findings between transformational leadership and innovation behaviour could be due to differences in the sample populations compared to previous studies. This study was open to any employed Australian over 18 years of age. In contrast, all but one of the previous studies targeted selective populations. For example, Afsar et al. (2014) drew their sample from employees in companies considered by Forbes magazine to be the five most innovative in China. Their deliberate sampling strategy was designed to test the relationship between transformational leadership and innovation in environments where the pressures on leadership to drive innovation could be considered to be 'above average'. Similarly, Reuvers et al. (2008) sampled from a very specific population, namely multi-disciplinary teams within hospitals, choosing only teams that included four different functional groups and an identifiable team leader. Nusair et al. (2012) were less specific in their study of innovation and transformational leadership, but they did sample only from within public service organisations. One common feature of the sample populations among the majority of previous studies is that respondents were all employees in large, established, hierarchical organisations (e.g. public bureaucracies, hospitals, manufacturing companies, service companies etc.). Because the present study did not control for organisation type or size, it's possible that these variables influenced the result. For example, company size has been shown to play a role in transformational leadership and innovation behaviour. Khan et al. (2009) found that company size moderates the relationship between transformational leadership and innovation, whereby the larger the company, the stronger the relationship between the two variables. And in a study of transformational leadership among CEOs, D. Jung et al. (2008) found that the larger the company, the greater the level of innovation.

\subsection{Meaningful Work and Innovation}

Consistent with expectations, this study found a significant and positive relationship between meaningful work and innovation. In other words, the more meaningful an employee found their work, the greater the level of innovation behaviour they exhibited. This is consistent with previous studies by Pradhan and Jena (2019) and Singh et al. (2020), which found that meaningful work is positively related to innovation behaviour.

The finding that meaningful work is the only predictor of innovation behaviour when considering meaningful work and transformational leadership in the same model is, to the authors' knowledge, one of the first times this relationship has been directly and empirically demonstrated using psychometrically reliable and valid measures. It suggests that organisations can potentially improve innovation behaviour by focusing on the factors that encourage employees to view their work as more meaningful. For a start, organisations interested in improving innovation are advised to take the concept of meaningful work seriously. They should ask themselves: are we paying enough attention to our employees' 
sense of meaning; what are the barriers to meaningful work in our organisation; are we committed to trying to make work more meaningful? While a novel idea for many organisations, having open and honest conversations about meaningful work could be an important part of developing a more effective innovation strategy. If fruitful, these initial discussions may lead to the adoption of processes designed to explicitly measure, monitor, and foster among employees a greater sense of meaning as it relates to their work and innovation behaviour. A greater focus on the topic of meaning among employees may also have positive secondary benefits beyond innovation, such as improved work engagement, organisational commitment and job satisfaction, as has been demonstrated elsewhere.

The findings in this study also support the theorised but largely untested idea that meaningful work plays an important role in influencing innovation behaviour, as suggested in the recent revision of their widely-cited dynamic componential model of creativity and innovation in organisations (e.g. Amabile \& Pratt, 2016; Amabile, 1988). Given the preponderance of research attention paid to leadership, particularly in relation to innovation, these findings suggest further investigation into the dynamic interplay between meaningful work and innovation is warranted.

The finding that transformational leadership did not predict innovation suggests that innovation strategies that privilege leadership over meaning may be less effective than ones that pay due attention to employees' experiences of meaningful work. Organisations interested in innovation may benefit by reflecting on their investments in developing transformational leadership capabilities, and specifically, whether such investments would benefit from a comparable focus on meaningful work. In a similar vein, organisations should be alert to the implications of leadership behaviours that may discourage or dampen employees' sense of meaning (e.g. Bailey \& Madden, 2016).

\section{Limitations}

A key limitation of this study is the generalisability of the results. The fact that the sample in this study was so broad (i.e. an open sample of employed adults) makes it difficult to generalise the results to specific populations, particularly to large hierarchical organisations or to smaller, flatter organisations such as start-ups. Also, because the sample population was limited to Australian employees, it's also potentially difficult to generalise the results to other cultures. It's been shown that national culture can influence organisational culture, including leadership style and employee behaviour (House et al., 2004). Lukes and Stephan (2017) also argue that national culture plays a role in innovation.

\section{Implications for Future Research}

Future studies could focus on longitudinally testing the relationships between meaningful work and innovation, including comparisons from specific target populations, such as large, hierarchical organisations or small, flat organisations, as well as within different national cultures. Future studies could also explore the mechanisms through which meaningful work influences innovation, helping leaders and employees gain a more nuanced understanding of what each can do to encourage both innovation and meaningful work within their 
organisations.

\section{References}

Afsar, B., F. Badir, Y., \& Bin Saeed, B. (2014). Transformational leadership and innovative work behavior. Industrial Management \& Data Systems, 114(8), 1270-1300, doi:10.1108/imds-05-2014-0152.

Allan, B. A., Duffy, R. D., \& Douglass, R. (2015). Meaning in life and work: A developmental perspective. The Journal of Positive Psychology, 10(4), 323-331, doi:10.1080/17439760.2014.950180.

Amabile, T. M. (1988). A model of creativity and innovation in organizations. In B. S. Cummings (Ed.), Research in Organizational Behaviour (pp. 123-167). Greenwich: JAI Press.

Amabile, T. M., \& Pratt, M. G. (2016). The dynamic componential model of creativity and innovation in organizations: Making progress, making meaning. Research in Organizational Behavior, 36, 157-183. https://doi.org/10.1016/j.riob.2016.10.001

Amabile, T. M., Schatzel, E. A., Moneta, G. B., \& Kramer, S. J. (2004). Leader behaviors and the work environment for creativity: Perceived leader support. The Leadership Quarterly, 15(1), 5-32. https://doi.org/10.1016/j.leaqua.2003.12.003

Arnold, K. A., Turner, N., Barling, J., Kelloway, E. K., \& McKee, M. C. (2007). Transformational leadership and psychological well-being: The mediating role of meaningful work. Journal of Occupational Health Psychology, 12(3), 193-203., https://doi.org/10.1037/1076-8998.12.3.193

Arnoux-Nicolas, C., Sovet, L., Lhotellier, L., Di Fabio, A., \& Bernaud, J.-L. (2016). Perceived Work Conditions and Turnover Intentions: The Mediating Role of Meaning of Work. [Original Research]. Frontiers in Psychology, 7(704). https://doi.org/10.3389/fpsyg.2016.00704

Aryee, S., Walumbwa, F. O., Zhou, Q., \& Hartnell, C. A. (2012). Transformational Leadership, Innovative Behavior, and Task Performance: Test of Mediation and Moderation Processes. Human Performance, 25(1), 1-25. https://doi.org/10.1080/08959285.2011.631648

Avolio, B. J., Bass, B. M., \& Jung, D. I. (1999). Re-examining the components of transformational and transactional leadership using the Multifactor Leadership Questionnaire. $\begin{array}{llll}\text { Occupational and Organizational } & \text { Psychology, } & 71, & 21 .\end{array}$ https://doi.org/10.1348/096317999166789

Bailey, C., \& Madden, A. (2016). What makes work meaningful - or meaningless. MIT Sloan Management Review, 57(4), 53.

Bass, B. M. (1999). Two Decades of Research and Development in Transformational Leadership. European Journal of Work and Organizational Psychology, 8(1), 9-32, https://doi.org/10.1080/135943299398410 
Bass, B. M., \& Riggio, R. E. (2006). Transformational Leadership (2nd ed.). Mahwah, NJ: Taylor and Francis.

Bawuro, F. A., Shamsuddin, A., Wahab, E., \& Usman, H. (2019). Mediating Role of Meaningful Work in the Relationship between Intrinsic Motivation and Innovative Work Behaviour. International Journal of Scientific and Technology Research, 8(9), 2076-2084.

Cai, W., Lysova, E. I., Khapova, S. N., \& Bossink, B. A. G. (2018). Servant Leadership and Innovative Work Behavior in Chinese High-Tech Firms: A Moderated Mediation Model of Meaningful Work and Job Autonomy. Frontiers in Psychology, 9. https://doi.org/10.3389/fpsyg.2018.01767

Carless, S. A., Wearing, A. J., \& Mann, L. (2000). A Short Measure of Transformational Leadership. Journal of Business and Psychology, 14(3), 389-405. https://doi.org/10.1023/a:1022991115523

Chen, S., Wang, M., \& Lee, S. (2018). Transformational leadership and voice behaviors: The mediating effect of employee perceived meaningful work. Personnel Review, 47(3), 694-708. http://dx.doi.org.ezproxy.uws.edu.au/10.1108/PR-01-2017-0016

Crossan, M. M., \& Apaydin, M. (2010). A Multi-Dimensional Framework of Organizational Innovation: A Systematic Review of the Literature. Journal of Management Studies, 47(6), 1154-1191. https://doi.org/10.1111/j.1467-6486.2009.00880.x

De Jong, J., \& Den Hartog, D. (2010). Measuring Innovative Work Behaviour. Creativity and Innovation Management, 19(1), 23-36. https://doi.org/10.1111/j.1467-8691.2010.00547.x

Fairlie, P. (2011). Meaningful Work, Employee Engagement, and Other Key Employee Outcomes. Advances in Developing Human Resources, 13(4), 508-525. https://doi.org/10.1177/1523422311431679

Friedrich, T. L., Mumford, M. D., Vessey, B., Beeler, C. K., \& Eubanks, D. L. (2010). Leading for Innovation. International Studies of Management \& Organization, 40(2), 6-29. https://doi.org/10.2753/IMO0020-8825400201

Frosch, K. H. (2011). Workforce Age and Innovation: A Literature Survey. International Journal of Management Reviews, 13(4), 414-430, https://doi.org/10.1111/j.1468-2370.2011.00298.x

Geldenhuys, M., Laba, K., \& Venter, C. M. (2014). Meaningful work, work engagement and organisational commitment. SA Journal of Industrial Psychology, 40(1), 1-10, https://doi.org/10.4102/sajip.v40i1.1098

Gronum, S., Steen, J., \& Verreynne, M. L. (2015). Business model design and innovation: Unlocking the performance benefits of innovation. Australian Journal of Management, 41(3), 585-605. https://doi.org/10.1177/0312896215587315

Hammond, M. M., Neff, N. L., Farr, J. L., Schwall, A. R., \& Xinyuan, Z. (2011). Predictors of Individual-Level Innovation at Work: A Meta-Analysis. Psychology of Aesthetics, 
Creativity \& the Arts, 5(1), 90-105. https://doi.org/10.1037/a0018556.

House, R. J., Hanges, P. J., Javidan, M., Dorfman, P. W., \& Gupta, V. (2004). Culture, leadership, and organizations: The GLOBE study of 62 societies. Thousand Oaks, Calif.: Sage Publications.

Jung, D., Wu, A., \& Chow, C. W. (2008). Towards understanding the direct and indirect effects of CEOs' transformational leadership on firm innovation. The Leadership Quarterly, 19(5), 582-594. https://doi.org/10.1016/j.leaqua.2008.07.007

Jung, H. S., \& Yoon, H. H. (2016). What does work meaning to hospitality employees? The effects of meaningful work on employees' organizational commitment: The mediating role of job engagement. International Journal of Hospitality Management, 53, 59-68. https://doi.org/10.1016/j.ijhm.2015.12.004.

Khalili, A. (2016). Linking transformational leadership, creativity, innovation, and innovation-supportive climate. Management Decision, 54(9), 2277-2293. https://doi.org/10.1108/MD-03-2016-0196.

Khan, R., Rehman, A. U., \& Fatima, A. (2009). Transformational leadership and organizational innovation: Moderated by organizational size African Journal of Business Management 3(11), 6. https://doi.org/10.5897/AJBM09.203

Kuratko, D. F., Covin, J. G., \& Hornsby, J. S. (2014). Why implementing corporate innovation is so difficult. Business Horizons, 57(5), 647-655. https://doi.org/10.1016/j.bushor.2014.05.007

Lepisto, D. A., \& Pratt, M. G. (2017). Meaningful work as realization and justification. Organizational Psychology Review, 7(2), 99-121. https://doi.org/10.1177/2041386616630039

Lips-Wiersma, M., \& Wright, S. (2012). Measuring the Meaning of Meaningful Work. Group \& Organization Management, 37(5), 655-685. https://doi.org/10.1177/1059601112461578

Lips-Wiersma, M., Wright, S., \& Dik, B. (2016). Meaningful work: differences among blue-, pink-, and white-collar occupations. Career Development International, 21(5), 534-551. https://doi.org/10.1108/CDI-04-2016-0052

Lukes, M., \& Stephan, U. (2017). Measuring employee innovation: A review of existing scales and the development of the innovative behavior and innovation support inventories across cultures. International Journal of Entrepreneurial Behavior \& Research, 23(1), 136-158. https://doi.org/10.1108/IJEBR-11-2015-0262

Makkonen, T., \& Inkinen, T. (2013). nnovative Capacity, Educational Attainment and Economic Development in the European Union: Causal Relations and Geographical

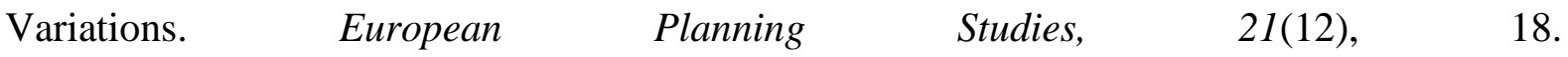
https://doi.org/10.1080/09654313.2012.722968

Michaelson, C. (2010). The Importance of Meaningful Work. MIT Sloan Management 
Review, 51(2), 12-13.

Mumford, M. D., Gibson, C., Giorgini, V., \& Mecca, J. (2014). Leading for creativity: People, Products and Systems. In D. V. Day (Ed.), The Oxford Handbook of Leadership and Organizations (pp. 757-782). New York, NY: Oxford University Press.

Nählinder, J., Tillmar, M., \& Wigren-Kristoferson, C. (2015). Towards a Gender-Aware understanding of innovation: A three-dimensional route. International Journal of Gender and Entrepreneurship, 7(1), 20. https://doi.org/10.1108/IJGE-09-2012-0051

Nusair, N., Ababneh, R., \& Kyung Bae, Y. (2012). The impact of transformational leadership style on innovation as perceived by public employees in Jordan. International Journal of Commerce and Management, 22(3), 182-201. https://doi.org/10.1108/10569211211260283

Oke, A., Munshi, N., \& Walumbwa, F. O. (2009). The Influence of Leadership on Innovation Processes and Activities. Organizational Dynamics, 38(1), 64-72. https://doi.org/10.1016/j.orgdyn.2008.10.005

Pradhan, S., \& Jena, L. K. (2019). Does Meaningful Work Explains the Relationship Between Transformational Leadership and Innovative Work Behaviour? Vikalpa: The Journal for Decision Makers, 44(1), 30-40. https://doi.org/10.1177/0256090919832434

Pradhan, S., \& Pradhan, R. K. (2016). Transformational Leadership and Job Outcomes: The Mediating Role of Meaningful Work. Global Business Review, 17(3_suppl), 173S-185S. https://doi.org/10.1177/0972150916631211

PricewaterhouseCoopers (2014). Deciding with data. Retrieved from http://www.pwc.com.au/consulting/assets/publications/data-drive-innovation-sep14.pdf

Reuvers, M., Van Engen, M. L., Vinkenburg, C. J., \& Wilson-Evered, E. (2008). Transformational Leadership and Innovative Work Behaviour: Exploring the Relevance of Gender Differences. Creativity and Innovation Management, 17(3), 227-244. https://doi.org/10.1111/j.1467-8691.2008.00487.x

Scott, S. G., \& Bruce, R. A. (1994). Determinants of innovative behavior: A path model of individual innovation in the workplace. Academy of Management Journal, 37(3), 580. https://doi.org/10.2307/256701

Seligman, M. E. P., Steen, T. A., Park, N., \& Peterson, C. (2005). Positive Psychology Progress: Empirical Validation of Interventions. American Psychologist July/August, 60(5), 410-421. https://doi.org/10.1037/0003-066X.60.5.410

Shunlong, X., \& Weiming, Z. (2012). The Relationships between Transformational Leadership, LMX, and Employee Innovative Behavior. The Journal of Applied Business and Economics, 13(5), 87-96.

Singh, N., Bamel, U., \& Vohra, V. (2020). The mediating effect of meaningful work between human resource practices and innovative work behavior: a study of emerging market. Employee Relations: The International Journal, 43(2), 459-478. 
https://doi.org/10.1108/ER-04-2020-0150

Sparks, J. R., \& Schenk, J. A. (2001). Explaining the effects of transformational leadership: an investigation of the effects of higher-order motives in multilevel marketing organizations. Journal of Organizational Behavior, 22(8), 849-869. https://doi.org/10.1002/job.116

Steger, M. F., Dik, B. J., \& Duffy, R. D. (2012). Measuring Meaningful Work. Journal of Career Assessment, 20(3), 322-337. https://doi.org/10.1177/1069072711436160

Steger, M. F., Dik, B. J., \& Shim Y. (In press). Assessing meaning and satisfaction at work. In S. J. Lopez (Ed.), The Oxford handbook of positive psychology assessment. Oxford, U.K.: Oxford University Press.

Tabachnick, B. G., \& Fidell, L. S. (2014). Using multivariate statistics (6th ed.). Harlow, Essex: Pearson Education Limited.

West, M. A. (2002). Ideas are Ten a Penny: It's Team Implementation not Idea Generation that Counts. Applied Psychology, 51(3), 411-424. https://doi.org/10.1111/1464-0597.01006

\section{Copyright Disclaimer}

Copyright for this article is retained by the author(s), with first publication rights granted to the journal.

This is an open-access article distributed under the terms and conditions of the Creative Commons Attribution license (http://creativecommons.org/licenses/by/3.0/). 